\title{
The First Monograph of Ukrainian Soil Scientists on the Holocene Evolution of Soils*
}

\author{
Yu. G. Chendev \\ Belgorod State University, ul. Pobedy 85, Belgorod, 308015 Russia \\ Received September 17, 2009
}

DOI: $10.1134 / \mathrm{S} 1064229310050133$

After the publication of the doctorate thesis abstract of V.P. Zolotun (1974), which gave a powerful impulse for the development of soil-evolutionary investigations in Russia, in Ukraine, new works on the problems of soil evolution did not appear for a long time. The situation began to change in 2007 when, at the Institute of Geography of the Ukrainian National Academy of Sciences, A.G. Parkhomenko prepared his PhD thesis Development of Holocene Soils of the Middle Dnepr River Basin (scientific superviser Zh.N. Matviishina). In 2008, Ukrainian science got enriched with the first monograph on the evolution of soils in Ukraine in the Holocene. The authors of the monograph are Prof. Yurii Mikhailovich Dmitruk (Chernovitsy National University, Dr. Sci. (Geography)) Zhanna Nikolaevna Matviishina (Head of the Department of Paleogeography, Institute of Geography, Ukrainian National Academy of Sciences), and Ivan Ivanovich Slyusarchuk (postgraduate, Chernovitsy National University; scientific superviser Yu.M. Dmitruk).

The monograph presents the results of a comparative analysis of soils related to Trayan Ramparts, archeological monuments of the Iron Age that were studied in the territory of Ternopol oblast. The main method of the investigations was the method of chronological series (chronoseries) for the recent and buried soils. The studies were carried out in zonal landscapes of the humid forest-steppe and broad-leaved forests (Ivanov factor 1.4-1.5) on four key plots on which reference soils were formed under the broadleaved forests before their cultivation. The present-day land use variants are natural broad-leaved forests, croplands, and pastures. Judging by the absolute age of the humus in the upper horizons of the buried soils studied (2430-3290 years ago, uncalibrated dating), the part of the Trayan Ramparts investigated by the authors might have been created within the range of 1500 to 2000 years ago, i.e., in the first half of the Holocene Subatlantic period. Thus, the results based on the comparison of the buried and reference soils and those

\footnotetext{
*Yu.M. Dmitruk, Zh.N. Matviishina, and I.I. Slyusarchuk, Soils of Trayan Ramparts: Evolutionary and Ecological-Genetic Analysis. Chernovtsy: Ruta, 2008. 228 pp. (in Ukrainian).
}

formed on the banks revealed the specific features of the soil cover at the last Late Holocene stage of its evolution.

Based on the results obtained on all the key plots, the authors concluded that the natural trend of the Late Holocene evolution of the soils in the broadleaved forest and forest-steppe zones (within the Podol'e and the Dnestr-Zbruch interfluve) was the formation of texturally differe ntiated gray forest soils from the chernozems with less differentiated profiles due to the expansion of forests over the meadowsteppe landscapes, which was favored by the humidization of the climate in the Holocene Subatlantic period.

In the chapter entitled Problems and Regularities of the Holocene Soils Evolution, the authors characterize in detail the concepts of the evolution of the Holocene soils (mainly in the territory of the East-European Plain). The results of many specialists in Ukraine, Russia, and foreign countries are presented. The material is divided into several sections: The Ecosystemic Aspect of Soil Evolution, Estimates of the Buried Holocene Soils, Morphology of the Buried Soils and Pedogenetic Processes, The Particle-Size Composition, The Humus and Organic Matter, Carbonates, The Content of Chemical Elements in Buried Soils, and The Dynamics and Soil-Forming Processes. The chapter entitled the Methodology of Research and Physiographic Characterization of the Territory Studied presents the methods of the studies, the current conditions, and the components of the environment where the soil cover of the Nadzbruch'e region is formed. The chapter Morphological-Morphometric Characterization of the Zonal and Buried Soils of the Nadzbruch'e chronoseries shows the specific features of the morphogenetic structure of the soils investigated. The rest of the chapters in this work are devoted to the assessment and comparison of the physical, physicochemical, and chemical properties of the soils, as well as to the distribution of the total contents of heavy metals and their mobile compounds in the profiles of the buried, background, and newly formed soils of the banks. The main geochemical difference between the buried 
and recent soils is the higher mobility of almost all the heavy metals in the latter, whereas their total content practically does not change. The differences in the profile distribution of the heavy metals related to the changes in their radial and lateral migration flows were also revealed. The last chapter of the monograph entitled Regularities of the Soil Evolution in the Nadzbruch'e Region contains the main conclusions concerning the research.

The cluster analysis of various soil characteristics used by the authors deserves special attention. This analysis gives an idea of the relationships between the buried, background, and newly formed soils on each of the sample plots and in the whole geographical region studied.
A number of problems discussed by the authors of the monograph are beyond the scope of the pure natural evolution of the soils. The different economic uses of the reference soils allowed the authors to discuss and present some interesting aspects of the agrotechnogenic evolution and heavy metal pollution of the soils.

The monograph of Yu.M. Dmitruk, Zh.N. Matviishina, and I.I. Slyusarchuk (300 copies) was only published in Ukrainian, which poses some problems for its reading by Russian-speaking specialists. Therefore, the author of this review hopes that, in the immediate future, a Russian version of this monograph will appear. Undoubtedly, it will be useful for many specialists in soil science, paleogeography, landscape science, and ecology. 